\title{
Autorregulação e poder disciplinar das bolsas de valores, mercadorias e futuros
}

\author{
Self-regulation and disciplinary power of securities, commodities \\ and futures exchanges
}

GLAUCO DA ROCHA ${ }^{a}$

\section{RESUMO}

Este artigo analisa a origem e características mais elementares das bolsas de valores, mercadorias e futuros, com enfoque na compreensão do poder disciplinar desempenhado por estas instituições autorregulatórias. Procurase demonstrar a sua estrutura, funcionamento e importância na supervisão e fiscalização do cumprimento às normas editadas pelas mesmas (no Brasil, atualmente concentradas na BM\&FBovespa).

Palavras-chave: Poder disciplinar. Bolsa de Valores, Mercadorias e Futuros. Autorregulação.

\begin{abstract}
This article analyzes the origin and most elementary characteristics of the Securities, Commodities and Futures Exchanges, with a focus on understanding the disciplinary power played by these self-regulating entities. It shall demonstrate their structure, functioning and importance in the supervision and monitoring of compliance with the regulations enacted by them (in Brazil, currently concentrated on BM\&FBovespa).

Keywords: Disciplinary power. Securities, Commodities and Futures Exchanges. Self-regulation.
\end{abstract}

\section{CONSIDERAÇÕES SOBRE O TEMA}

Pretende-se, no presente artigo, analisar: (i) a autorregulação, examinando sua origem, conceito, modalidades, fundamentos, vantagens e desvantagens; (ii) as bolsas de valores, mercadorias e futuros, suas raízes históricas, regime jurídico de formação, função e os tipos de normas autorregulatórias; para, enfim, verificarmos (iii) o poder disciplinar das bolsas, suas características gerais, histórico e atual formatação.

\section{AUTORREGULAÇÃO: ORIGEM, CONCEITO, MODALIDADES, FUNDAMENTOS, VANTAGENS E DESVANTAGENS}

Neste item analisaremos de maneira expositiva a origem, conceito, modalidades, fundamentos, vantagens e desvantagens da autorregulação.
2.1 A origem da noção de autorregulação remonta às cidades livres, na Europa dos séculos XI e XII, a partir de comerciantes organizados em irmandades, grêmios ou guildas, que possuíam autonomia para poder elaborar leis e manter tribunais de justiça.

As chamadas "feiras", acontecimento principal das cidades livres recebiam pouca interferência do Senhor Feudal, que se limitava, na maioria dos casos, à cobrança de tributos.

Assim, as feiras eram reguladas pelos próprios mercadores, que estabeleciam regras como estabelecimento de preços e proibição de propagandas ${ }^{1}$. Ou seja, em seu próprio seio, por seus próprios membros, eram estabelecidas regras que seriam aplicadas para que o comércio ali se desenvolvesse, sem o que não haveria segurança nem funcionamento apropriado para tal intento.

É a partir dessas feiras, portanto, que se dá início historicamente ao fenômeno da "autorregulação" de maneira institucionalizada. 
2.2 Vejamos agora o conceito de regulação. Para Rachel Sztajn,

[r] egular significa formular e impor regras em forma de integração do Estado no domínio econômico. [...] Regulação pode ser entendida como o conjunto de regras predispostas por um órgão ou agência da administração indireta, visando a fiscalizar e garantir, pela observância ou cumprimento, a disciplina de certas atividades ou setores da atividade econômica ${ }^{2}$.

Ou seja, regular implica tanto editar normas quanto aplicar tais regras, fiscalizando seu cumprimento ${ }^{3}$.

A autorregulação, de maneira semelhante, também envolve formulação e imposição de regras; mas, por outro lado, pode ser enxergada a partir de três vieses ${ }^{4}$.

O primeiro viés, o econômico, é representado pela capacidade de o mercado funcionar de maneira equilibrada e atomizada, sem a intervenção de normas artificiais e planejadoras externas ao próprio mercado. Trata-se de um conceito decorrente da escola neoclássica de economia, com fulcro na mão invisível de Adam Smith.

O viés operacional, extraído da visão de Vital Moreira $^{5}$, reconhece que a autorregulação constitui regras impostas e não fruto de "forças equilibradoras", observadas por uma coletividade, exsurgidas de um fenômeno privado, extraestatal.

O terceiro viés, jurídico - mais importante para o presente artigo -, consiste no conjunto de normas autovinculantes que determinado grupo impõe para si, espontaneamente ou por determinação do Estado. Aqui se tem presente a função de normatizar e fiscalizar a atividade, operações e os membros do grupo que estão sujeitos à autorregulação.

2.3 Cumpre observar que a autorregulação pode ser espontânea ou decorrente de determinação estatal. Nesse contexto, para Trindade e $\operatorname{Santos}^{6}$ a autorregulação pode ser classificada em duas modalidades: uma de natureza privada e outra de natureza pública.

A modalidade privada seria a autorregulação de base voluntária, a partir de instrumentos de direito privado, como medidas contratuais, em que se cria uma relação de subordinação entre a entidade o autorregulador e os membros autorregulados.

A modalidade pública é aquela que pode decorrer do reconhecimento de uma determinada atividade de natureza privada pelo Estado, ou, aquela criada por iniciativa estatal. Trata-se de autorregulação de base legal, a partir de instrumentos de direito público. Em outras palavras, ocorre "quando as instâncias de auto-regulação são impostas ou estabelecidas pelo Estado, embora as entidades auto-reguladoras per- maneçam privadas e independentes do Estado"7. A entidade privada é reconhecida pelo Estado como autoridade competente para a produção e imposição daquelas regras que regulam a atividade.

2.4 Dentre os fundamentos que justificariam a autorregulação, no caso das Bolsas ${ }^{8}$, pode-se destacar quatro principais, abaixo verificados.

Segundo Otavio Yazbek, o principal fundamento que justifica a autorregulação baseia-se na necessidade natural das agremiações de estabelecerem normas para o convívio interno entre seus membros, no sentido de ordenarem as suas atividades ${ }^{9}$.

Luciana Pires Dias, com base na teoria dos jogos, descreve a autorregulação como corolário da estratégia cooperativa, a qual possui as seguintes premissas: (i) todos os jogadores são identificáveis, (ii) todos os jogadores se beneficiam do aumento de volume de negócios, liquidez dos títulos e do acesso às informações (seus interesses convergem e o resultado da interação favorece as partes), (iii) as relações são contínuas, os jogadores cruzam-se diariamente em transações; (iv) o futuro das relações é indefinido. Para essa teoria, cooperar produziria mais resultados positivos para os jogadores do que se estes não cooperassem, e, para tanto, a autorregulação, enquanto forma de cooperação, estimularia o desenvolvimento da atividade econômica das partes envolvidas ${ }^{10}$.

Outro fundamento é aquele baseado na teoria dos custos de transação, em que a autorregulação desempenhada pelas Bolsas reduziria custos de transação com: (i) mensuração da mercadoria; (ii) assimetria de informações; (iii) dificuldades de interação e seleção dos agentes; e, (iv) dificuldade de execução dos contratos. Assim, a autorregulação também desempenharia um papel importante ao reduzir os custos de transação entre as partes.

O quarto fundamento, mas não menos importante, consistiria em atuar de maneira complementar à regulação feita pelos entes estatais ou como uma alternativa à heterorregulação estatal, adentrando em campos que não são de interesse do Estado ou que lhe são muito custosos para regular ${ }^{11}$.

2.5 Por fim, quanto às vantagens e desvantagens da autorregulação em relação à regulação Estatal, tem-se, comumente, o destaque das seguintes vantagens: (i) a instituição autorreguladora possui maior proximidade com a atividade regulada; (ii) é mais ágil na revisão de normas e procedimentos; (iii) possui maior flexibilidade para imposição de normas e princípios de conteúdo ético (exame de justiça, ao invés de legalidade); (iv) os participantes tendem a atribuir maior importância 
ao cumprimento das normas, pois foram envolvidos com a sua elaboração; e, (v) afasta-se a discussão quanto à legitimidade da interferência da instituição autorreguladora, pois os membros, voluntariamente sujeitaram-se às suas normas e procedimentos ${ }^{12}$.

Já como desvantagens são apontadas as seguintes: (i) tanto o conflito de interesses de certos membros quanto o corporativismo de toda a classe pode levar à diminuição do grau de exigência da aplicação das sanções, incentivando condutas prejudiciais às partes mais fracas; e, (ii) frequentemente verificamse lacunas nas normas legais quanto aos limites das atuações estatal e privada e os poderes de cada uma, o que pode causar insegurança jurídica quanto à força e legitimidade das decisões ${ }^{13}$.

Feitas essas breves considerações, ingressemos, a partir de agora, nas raízes históricas das Bolsas até a atual formatação da BM\&FBovespa, no regime jurídico de formação das bolsas, sua função e tipos de normas autorregulatórias.

\section{AS BOLSAS: RAÍZES HISTÓRICAS, A BM\&FBOVESPA, REGIME JURÍDICO DE FORMAÇÃO DAS BOLSAS, FUNÇÃO, TIPOS DE NORMAS AUTORREGULATÓRIAS.}

3.1 Na idade antiga já havia referências quanto a uma versão preliminar das bolsas de comércio, com o emporium na Grécia e o collegium mercatorum na Itália. Mais adiante, na idade média, faz-se menção aos termos loggie, na Itália, e Lonjas, na Espanha.

O termo 'Bolsa', propriamente dito, remonta ao Século XIII, na cidade de Bruges, na Bélgica, onde a Família Van der Beurse (que significa 'da Bolsa') possuía um hotel em frente a uma das principais praças da cidade, chamado 'Ter Beurse' (traduzido como 'ao sinal da bolsa'). Na frente do hotel havia o escudo da família, que continha três pequenas bolsas no centro (brasão ao lado). Nessa época os comerciantes faziam referência às bolsas do escudo para designar a praça na qual se reuniam, que era o principal centro econômico e financeiro da cidade ${ }^{14}$.

Entre nós, no Código Comercial de 1850, havia apenas a referência a "Praça do Comércio". A primeira referência ao termo "Bolsa" veio no Regulamento Interno da Junta de Corretores da Praça do Rio de Janeiro, em 1877, e, finalmente, de maneira positivada, no Decreto 1359 de 1893.
3.2 Segundo Oscar Barreto Filho ${ }^{15}$, a primeira Bolsa Comercial de caráter internacional estava localizada em Antuérpia, em 1531, na Bélgica, quando os comerciantes passaram a se reunir em uma edificação própria, após o enfraquecimento financeiro de Bruges no Século XV. Mas as bolsas de feição moderna advieram com a Bolsa de Valores de Londres (LSE), cuja origem remonta o ano de 1698, e que, em 1773, modificou-se adotando características tipicamente corporativas e autorregulatórias.

3.3 Passando para a análise de nossa história nacional, Arnoldo Wald e Nelson Eizirik atentam que em 1809 já havia corretores atuando na cidade do Rio de Janeiro ${ }^{16}$. No entanto, foi apenas no Decreto 417 de 1845 que os corretores receberam definição legal e sua atividade foi dividida em corretagem de fundos públicos, de navios e de mercadorias. Nesse decreto previa-se que seriam nomeados pelo Tribunal do Tesouro, na Corte, e pelas Tesourarias, nas Províncias. Se fossem culpados pelas contravenções dispostas no Decreto, poderiam ser suspensos ou demitidos pela autoridade que os havia nomeado ${ }^{17}$.

Com o Decreto 648 de 1849, foi regulada a Junta dos Corretores, dotada de poder decisório, podendo censurar, solver disputas e fiscalizar seus membros. Nessa época, o corretor recebia uma patente do Ministro da Fazenda, na Corte, e pelos Presidentes (Governadores) dos Estados, nas províncias. Tratava-se de um ofício público de caráter vitalício, com limite de $\operatorname{cargos}^{18}$.

A partir do Decreto 806 de 1851, os corretores passaram a ser nomeados pelo Tribunal do Comércio, que poderia multar, suspender e destituir corretores, com decisão recorrível ao Conselho do Estado (embrião do atual Conselho Monetário Nacional) ${ }^{19}$.

Em 1876, o Decreto 6.132 passou a prever expressamente a destinação de edifícios para as apregoações (locus fixo) ${ }^{20}$.

O Decreto 1.359 de 1893 transformou a Junta dos Corretores em Câmara Sindical, subordinada ao Ministro da Fazenda (e, posteriormente, à Secretaria da Fazenda dos Estados), e não mais ao Tribunal do Comércio, sendo os corretores nomeados pelo Presidente da República e pelos Governadores dos Estados ${ }^{21}$.

Em 1895, foi criada a Bolsa de Fundos Públicos de São Paulo (embrião da Bovespa), que hoje, após a união com a BM\&F, passou a se chamar BM\&FBovespa. Em 1935, tal entidade passou a se chamar Bolsa Oficial de Valores de São Paulo ${ }^{22}$. Aqui a Bolsa possuía câmara sindical, era subordinada ao Ministério da Fazenda e os corretores eram nomeados pelo Governador do Estado de São Paulo, com cargo vitalício. 
Já nessa época, muito se discutia a respeito da natureza das Bolsas, se públicas ou privadas, não obstante, o entendimento predominante pela doutrina comercialista era no sentido de que se tratavam de órgãos auxiliares do Estado, enquadradas como pessoas jurídicas de direito privado (embora fosse desprovida de personalidade jurídica) ${ }^{23}$.

Em meados da década de 60, houve uma reformulação do sistema financeiro nacional, com a edição das Leis 4.959/1964 e 4.728/1965 e com a Resolução CMN 39/1966. Houve então a chamada "despublicização" das Bolsas, que passaram a ser associações civis, constituídas por sociedades corretoras, abandonando-se, ainda, o caráter vitalício dos cargos de corretores ${ }^{24}$. Extinguiu-se também a figura da Câmara Sindical, que passou a ser o Conselho de Administração das Associações das Bolsas existentes.

Assim, em 1967, a Bolsa Oficial de Valores de São Paulo passou a se chamar Bolsa de Valores de São Paulo, sem subordinação à Secretaria da Fazenda dos Estados.

Após a crise econômica instalada a partir do início da década de 70, houve mais uma reforma com a Lei 6.385/76, que criou a Comissão de Valores Mobiliários - CVM e a Lei 6.404/76, que regulou as Sociedades por Ações, modernizando o nosso sistema financeiro e modelando a sua atual feição.

Afirmava-se que as Bolsas de Valores seriam instituições privadas, mas que, entretanto, necessitavam de autorização prévia de funcionamento, bem como regramento em linhas gerais pelo Estado ${ }^{25}$.

Nas últimas décadas do século passado, iniciou-se um processo de integração das Bolsas, que durou até o ano de 2000, quando ocorreu a concentração de toda a negociação de ações do país na Bovespa.

Em 2002 a prerrogativa de regulação geral da atividade das Bolsas, antes atribuída aos CMN - Conselho Monetário Nacional, foi transferida, com a Lei 10.411/02, para a CVM - Comissão de Valores Mobiliários.

Em 2005 o Sistema de Pregão Viva Voz foi substituído pelo sistema Mega Bolsa, trazendo importante modernização tecnológica.

O processo de "desmutualização"26 da Bolsa de Valores, ou seja, a sua transformação de associação para sociedade empresária, seguindo a tendência mundial, ocorreu em setembro de 2007.

Em outubro de 2007 a Instrução CVM no 461 deu novos contornos à atividade autorregulatória da CVM e das Bolsas, e, em novembro do mesmo ano, a Bovespa promoveu sua autolistagem no mercado de capitais.

Em maio de 2008 formou-se a BM\&FBovespa, a partir de uma série de atos societários que ocasionaram a reunião das atividades da Bovespa e da $\mathrm{BM} \& \mathrm{~F}$, como veremos adiante.
3.4 Por outro lado, em relação à $B M \& F-B o l s a$ de Mercadorias e Futuros, sua história é mais curta.

A Bolsa pioneira na negociação de operações a termo foi na verdade a Bolsa de Mercadorias de São Paulo (BMSP), criada em 1917. A BM\&F - Bolsa Mercantil e de Futuros foi criada apenas em 1985.

Em 1991, acordo operacional entre BMSP e a $\mathrm{BM} \& \mathrm{~F}$ deu origem a BM\&F - Bolsa de Mercadorias e Futuros. Em 1997, por um novo acordo operacional com a BBF - Bolsa Brasileira de Futuros, todas as negociações com derivativos no Brasil foram centralizadas na BM\&F.

Com a Lei 10.303 de 2001, a BM\&F passou a ser fiscalizada e regulada, em parte, pela CVM, assim como a Bolsa de Valores já o era desde 1976.

Em setembro de 2007, por um processo de desmutualização, listando-se no novo mercado em novembro do mesmo ano, para, em maio de 2008, unir-se à Bovespa sob a designação de BM\&FBovespa.

Esse processo de fusão de ambas as Bolsas se deu da seguinte forma.

Primeiro, a associação que antes era a Bovespa transformou-se em Sociedade Anônima, na BVSP Bolsa de Valores de São Paulo, na CBLC - Câmara Brasileira de Liquidação e Custódia, e na Bovespa Holding S.A, controladora das duas primeiras. A BVSP e a CBLC associaram-se, então, para a criação da BSM - Bovespa Supervisão de Mercados ${ }^{27}$.

Interessante notar que essa separação das atividades de autorregulação da Bolsa na BSM retrata a chamada separação estrutural descrita por Eizirik, Gaal, Parente e Henriques ${ }^{28}$, que consiste na criação de uma pessoa jurídica distinta da bolsa, com administração patrimônios próprios, com a prerrogativa de exercer, com exclusividade, as atividades atinentes à função regulatória das Bolsas, qual seja, a atual $\mathrm{BM} \& \mathrm{~F}$ Bovespa Supervisão de Mercados.

Ao mesmo tempo, a associação que antes era a BM\&F transformou-se em sociedade anônima, a BM\&F S.A.

Ato contínuo, a Bovespa Holding S.A. e BM\&F S.A. foram incorporadas pela BM\&F Bovespa S.A (sociedade criada para reunir as participações de ambas as Bolsas), transformando a primeira em subsidiária integral da BM\&FBovespa e extinguindo a segunda. Operacionalmente, foram destacadas as atividades da Bolsa em dois segmentos: o segmento Bovespa (para operações com valores mobiliários) e o segmento $\mathrm{BM} \& \mathrm{~F}$ (para operações com derivativos).

3.5 Finalizada essa exposição histórica a respeito das Bolsas, cumpre destacar, da lição de Ary Oswaldo Mattos Filho, o regime jurídico de formação das 
Bolsas. Para o referido autor, os regimes podem ser classificados em regime das bolsas liberais, das bolsas instituídas e das autorizadas ${ }^{29}$.

O primeiro, das bolsas liberais, também chamadas de livres ou privadas, existente já há alguns séculos, é aquele em que há interferência mínima do Estado, como implementado originalmente pela Inglaterra.

O segundo, das bolsas instituídas, ou oficiais, é aquele que depende de lei para a sua criação, originário do modelo francês.

Por último, o regime das bolsas autorizadas, dependentes de autorização ministerial, como ocorreu em França, Portugal e Austrália. Este último regime desenvolveu-se com maior força em 1934, nos Estados Unidos, com a criação da SEC - Securities Exchange Comission, mediante o Securities Exchange Act.

O nosso regime parece ter iniciado, na segunda metade do século XIX, como aquele regime francês, das bolsas instituídas ${ }^{30}$, passando, posteriormente, para o regime das bolsas autorizadas, e, hoje, com sua constituição e extinção determinada pela CVM.

Atualmente, a BM\&FBovespa pode ser classificada como entidade autorreguladora, de natureza privada, tipicamente corporativa, que exerce funções de interesse público, com autêntico poder de polícia, na condição de órgão auxiliar da CVM ("órgão de colaboração do Poder Público") e operando sob a supervisão desta, consoante Artigo 17, caput e $\S 1$, Lei $6.385 / 76^{31}$

A expressão órgãos auxiliares da CVM é problemática, conforme salienta Otávio Yazbek ${ }^{32}$, pois

ainda que determinadas atividades desenvolvidas pelas bolsas possam ser revestidas de caráter público [...], não há como fazer aquela extensão pura e simples do regime de direito público sem maiores ressalvas - trata-se, afinal, de entidades privadas, constituídas por iniciativa de agentes privados e que atuam em campo próprio da iniciativa privada, não se podendo nem mesmo, a rigor, falar em concessão ou delegação, a qualquer tipo, de serviço público.

Assim, para o referido autor, no Brasil há uma combinação bastante complexa entre autorregulação de natureza pública e privada ${ }^{33}$, nas palavras de Luciana Dias, seria um sistema hibrido que vaga entre os princípios de direito privado e os de direito público ${ }^{34}$.

3.6 Em relação às funções desempenhadas pelas Bolsas, as principais, segundo ensinam Eizirik, Gaal, Parente e Henriques, seriam: (i) "Fornecer um local ou sistema adequado à realização de operações com títulos, dotado de todos os meios necessários à pronta realização e visibilidade dos negócios, e que assegure, ademais, continuidade de preços e liquidez aos referidos títulos"; e, (ii) "Preservar padrões éticos de negociação, estabelecendo normas de comportamento para seus membros e fiscalizando a sua observância" 35 .

3.7 Porfim, no que tange aos tipos denormas autorregulatórias de que as Bolsas são dotadas, Otávio Yazbek destaca, de maneira simplificada, que existem: (i) as regras gerais de acesso aos sistemas de bolsa, que seriam aquelas que "englobam todos os mecanismos de ingresso de intermediários e de emissores de títulos, assim como as condições de listagem para a negociação"; e, (ii) as regras gerais de conduta, que "abarca [m] uma ampla gama de regras protetivas dos agentes ou garantidores dos mecanismos de negociação e dos processos de formação de preços, como regras operacionais, de comportamento, de prestação de informações etc". E salienta que "essas regras são, naturalmente, complementadas por um sistema de fiscalização e de aplicação de penalidades e restrições" 36 .

Entraremos, a partir de agora, justamente nessa parte da matéria, que trata do poder disciplinar das bolsas.

\section{O PODER DISCIPLINAR DAS BOLSAS: CARACTERÍSTICAS GERAIS, HISTÓRICO E ATUAL FORMATAÇÃO}

Neste tópico, analisaremos primeiramente algumas características gerais a respeito do poder disciplinar das Bolsas, passando para uma análise histórica do seu processo de formação aqui no Brasil, para, por último, analisarmos sua atual formatação.

Assim, vejamos, primeiramente, algumas características gerais.

4.1 O poder disciplinar das Bolsas, hoje no Brasil concentrado na BM\&FBovespa, pode ser conceituado como a faculdade ${ }^{37}$ - decorrente da sua capacidade autorregulatória, fulcrada em Lei e atos normativos da CVM e da própria Bolsa -, que a Bolsa possui de investigar, julgar e aplicar sanções aos membros sujeitos à sua esfera autorregulatória, bem como a capacidade de elaborar normas tendo em vista essa finalidade.

Utilizando de forma "emprestada" o conceito de poder disciplinar da CVM, referido em um dos artigos seminais sobre o tema, de autoria de José Alexandre Tavares Guerreiro, temos que o poder disciplinar consiste numa "faculdade de apurar, mediante inquérito administrativo, atos ilegais e práticas não equitativas de administradores e acionistas de companhias abertas, dos intermediários e dos demais participantes do mercado" 38 . 
Ele não exclui o poder disciplinar da CVM, mas deve ficar claro que a Bolsa atua sob a "supervisão" desta, na condição de "órgão auxiliar" para "fiscalizar os respectivos membros e as operações com valores mobiliários nelas realizadas" 39 . Nesse sentido, o $§ 1^{\mathrm{o}}$ do Artigo 8 da Lei 6.385/76 refere que: " $O$ disposto neste artigo [referente a competências da CVM] não exclui a competência das Bolsas de Valores, das Bolsas de Mercadorias e Futuros, e das entidades de compensação e liquidação com relação aos seus membros e aos valores mobiliários nelas negociados". E embora atue como órgão auxiliar da CVM, possui "autonomia administrativa, financeira e patrimonial" 40 .

Em razão desse regime de competências paralelas, por exemplo, via de regra, as decisões disciplinares da Bolsa (mais precisamente, da BSM - BM\&FBovespa Supervisão de Mercados) não poderão ser objeto de recurso à $\mathrm{CVM}^{41}$, ressalvada a decisão que tiver negado pedido de ressarcimento do Mecanismo de Ressarcimento de Prejuízos, por previsão expressa ${ }^{42}$.

Entretanto, como é supervisionada pela CVM, há um sistema de remessa de informações quanto aos julgamentos realizados pela $\mathrm{BSM}^{43}$.

Essa supervisão pode ser traduzida também em diversas atribuições da CVM que surtem efeitos relevantes na esfera de atuação da Bolsa, como, por exemplo, (i) a prerrogativa de aprovar regulamento de procedimentos a serem observados pela Bolsa em processos administrativos, (ii) a capacidade de editar normas gerais sobre condições de constituição e extinção da Bolsa, exercício de poder disciplinar, sobre seus membros, imposição de penas e casos de exclusão, (iii) competência para autorizar o funcionamento e extinção dos mercados organizados de valores mobiliários, (iv) a capacidade de verificar se os requisitos expedidos pela ICVM 461/07 estão sendo cumpridos pela Bolsa etc. ${ }^{44}$.

Curiosamente, em caminho inverso, há casos em que o processo administrativo da Bolsa pode irradiar efeitos sobre o processo administrativo da CVM. Por exemplo, na redução das penalidades que venham a ser aplicadas pela CVM no seu âmbito; e, em processos que tenham por objeto os mesmos fatos apurados pela Bolsa, no computo da pena máxima, que deve ser calculada somando-se a pena imposta pela Bolsa e aquela aplicada pela CVM, quando forem da mesma natureza ${ }^{45}$.

4.2 Por se tratar de órgão auxiliar da CVM, a Bolsa está sujeita a diversas normas direcionadas à administração pública. Como dissemos antes, essa questão é problemática, e isso se deve à relevância pública desses serviços. É difícil criar um liame, contudo, sobre até que ponto as normas de direito público podem ser aplicadas.

Não obstante, entendemos que o poder disciplinar da Bolsa deve encontrar, com alguns temperos, os mesmos limites gerais associados à Administração Pública, como aqueles previstos no Artigo $2^{\mathrm{O}}$ da Lei 9.784/99:

A Administração Pública obedecerá, dentre outros, aos princípios da legalidade, finalidade, motivação, razoabilidade, proporcionalidade, moralidade, ampla defesa, contraditório, segurança jurídica, interesse público e eficiência.

Inclusive aqueles previstos no parágrafo único do Artigo em apreço:

Nos processos administrativos serão observados, entre outros, os critérios de: I - atuação conforme a lei e o Direito; II - atendimento a fins de interesse geral, vedada a renúncia total ou parcial de poderes ou competências, salvo autorização em lei; III - objetividade no atendimento do interesse público, vedada a promoção pessoal de agentes ou autoridades; IV - atuação segundo padrões éticos de probidade, decoro e boa-fé; V - divulgação oficial dos atos administrativos, ressalvadas as hipóteses de sigilo previstas na Constituição; VI - adequação entre meios e fins, vedada a imposição de obrigações, restrições e sanções em medida superior àquelas estritamente necessárias ao atendimento do interesse público; VII - indicação dos pressupostos de fato e de direito que determinarem a decisão; VIII - observância das formalidades essenciais à garantia dos direitos dos administrados; IX - adoção de formas simples, suficientes para propiciar adequado grau de certeza, segurança e respeito aos direitos dos administrados; X - garantia dos direitos à comunicação, à apresentação de alegações finais, à produção de provas e à interposição de recursos, nos processos de que possam resultar sanções e nas situações de litígio; XI - proibição de cobrança de despesas processuais, ressalvadas as previstas em lei; XII - impulsão, de ofício, do processo administrativo, sem prejuízo da atuação dos interessados; XIII - interpretação da norma administrativa da forma que melhor garanta o atendimento do fim público a que se dirige, vedada aplicação retroativa de nova interpretação.

Como se vê, portanto, não é permitido à Bolsa agir fora dos limites legais e regulamentares, em conflito de interesses ou em abuso ou desvio de poder.

4.3 Vale referir que há critérios de julgamento também expressamente definidos no Regulamento da BSM, como: (i) atentar, além dos efeitos imediatos 
da decisão, para seus outros efeitos, "especialmente quanto ao aspecto educacional, ao aprimoramento da conduta do acusado e à credibilidade do mercado"; e, (ii) considerar, na aplicação das penalidades, "o arrependimento eficaz, o arrependimento posterior ou a circunstância de qualquer acusado, espontaneamente, confessar ou prestar informações sobre os atos e fatos apurados" 46 .

Adicionalmente, a sanção a ser aplicada em virtude da utilização do poder disciplinar repercutirá na esfera administrativa interna da instituição autorreguladora, não possuindo, por conseguinte, natureza penal. Ou seja, a gravidade da punição a ser aplicada ao condenado não experimentará tamanha força.

4.4 Em outra senda, poderia surgir dúvida, a respeito do espectro de atuação do poder disciplinar da Bolsa, se se poderia estendê-lo, por exemplo, aos investidores em geral.

A partir da autorização legal (Artigo 17, § 1ํㅡ, Lei 6.385/76) que habilita a Bolsa a fiscalizar as operações nelas realizadas, Guerreiro entende que tal extensão seria possível:

Daí a dúvida sobre a possível extensão do poder disciplinar das Bolsas de Valores a outros participantes do mercado, como seria o caso v.g., das companhias abertas, de seus administradores, de seus acionistas controladores ou não-controladores, e de investidores em geral. A dúvida se afastaria, porém, levando-se em conta a autorização legal que habilita as bolsas a fiscalizar as operações nelas realizadas ${ }^{47}$.

Essa questão encontra-se positivada também no Artigo 36 e 43 da ICVM 461/07 que determina ser de competência da Bolsa, "fiscalizar as operações realizadas nos mercados administrados pela entidade".

Na realidade, embora não se discorde da assertiva destacada acima, nos parece que essa extensão ao público investidor, na verdade, ocorre como vertente do poder de polícia exercido pela Bolsa, e não do poder disciplinar, propriamente dito.

Segundo Hely Lopes Meirelles, poder de polícia é a "faculdade de que dispõe a Administração Pública para condicionar e restringir o uso e o gozo de bens, atividades e direitos individuais, em benefício da coletividade ou do próprio Estado"48.

O Artigo 78 do Código Tributário Nacional define-o especificadamente:

Art. 78. Considera-se poder de polícia atividade da administração pública que, limitando ou disciplinando direito, interêsse ou liberdade, regula a prática de ato ou abstenção de fato, em razão de intêresse público concernente à segurança, à higiene, à ordem, aos costumes, à disciplina da produção e do mercado, ao exercício de atividades econômicas dependentes de concessão ou autorização do Poder Público, à tranqüilidade pública ou ao respeito à propriedade e aos direitos individuais ou coletivos.

A diferença de enfoque, a nosso ver, reside no fato de que o poder disciplinar visa aplicar sanções administrativas aos seus agentes e membros pela prática de infrações de caráter funcional, enquanto que o poder de polícia refere-se à restrição, condicionamento ou limitação do exercício de direitos e atividades econômicas dos particulares para preservar os interesses da coletividade. Nessa esteira, a extensão aos investidores ocorreria por força do poder de polícia, o qual é capaz de alcançar terceiros que não os seus membros ${ }^{49}$.

Para Luiz Felipe Calabro, a Bolsa exerce poder de polícia delegado, o qual se contrapõe ao poder de polícia originário. Aquele nasce mediante transferência legal e é limitado aos termos da delegação, caracterizando-se por atos de execução, nele está implícita a faculdade de aplicar sanções aos infratores, na forma regulamentar. O poder de polícia originário, por outro lado, nasce com a entidade que o exerce, de pleno exercício e consequente da própria natureza da entidade ${ }^{50}$.

4.5 Feitos esses comentários a respeito do conceito e características gerais do poder disciplinar, vejamos agora como se deu o processo de construção no Brasil deste poder em relação às Bolsas até sua configuração atual, a fim de entendermos sua estrutura e funcionamento vigentes.

$\mathrm{O}$ primeiro ato normativo referente à atividade dos corretores, o Decreto 417 de 1845 já dispunha, em seu Artigo 10, ainda de maneira incipiente, a possibilidade de suspensão ou demissão dos corretores que tivessem praticado contravenções previstas no Decreto: "Os Corretores que se acharem culpados de contravenção ás disposições deste Regulamento, serão, segundo as circumstancias, suspensos ou demittidos pela Autoridade que os nomeou".

Contudo, nesta época, os corretores ainda não se reuniam de maneira organizada e formalizada em uma instituição própria de corretores, e as sanções não eram aplicadas internamente por um ente formado pelos corretores; portanto, não era possível se falar ainda em autorregulação, e, consequentemente, em poder disciplinar das Bolsas.

Quatro anos mais tarde, o Decreto $n^{\mathrm{o}} 648$ de 1849 , passou a regulamentar a Junta dos Corretores, formada por cinco corretores, a qual, dentre outras atribuições (cfe. Artigo 58), competia: (i) "Exercer vigilancia sobre 
todos os Corretores para que se contenhão nos limites de suas funcções legaes", (ii) "censurar, e mesmo suspender até 6 mezes os Corretores"; (iii) "Fiscalisar que nenhum individuo sem titulo legal se intrometta nas funç̧ões de Corretor", nesse caos, aplicando multa aos infratores; e, (iv) "Decidir as contestações, que se suscitarem entre os Corretores relativamente ao exercicio legal de suas funcções". Aqui já se começava a verificar o embrião do poder disciplinar das Bolsas, mesmo que de maneira generalizada e abstrata. Porém, ressalva-se, não existiam Bolsas propriamente ditas, os corretores reuniam-se, à época, nas "praças do commercio".

A partir de 1851, embora ainda não tivessem o nome de "Bolsa de Valores", foram instituídas oficialmente no país por meio de vários decretos imperiais "casas de praça de comércio", que tratavam da intermediação de negócios no Rio de Janeiro, Bahia, Pernambuco, Maranhão e Pará.

Mais adiante, sob a égide do Decreto 1359 de 1893, passou a se fazer referência expressa às "Bolsas" como local onde se reuniam os corretores. A partir de então as Câmaras Sindicais passaram a substituir a Junta dos Corretores na fiscalização das atividades dos seus membros. A redação do seu Artigo 87 praticamente repetia a do Artigo 58 do Decreto 648/1849, podendo a Câmara ainda ordenar-lhes a apresentação dos seus livros e prescrever aos seus membros todas as medidas de precaução que julgar necessárias, interdizer-lhes a entrada na Bolsa, anular negociações com títulos negociados por quem não fosse corretor, e decidir as controvérsias que se suscitarem entre os corretores. As penas disciplinares eram impostas por deliberação da maioria da Câmara, ouvido previamente o corretor acusado. Digno de nota que, conforme expressa previsão legal, se um corretor se recusasse a exibir livros à Câmara, poderia ser obrigado a apresentá-los "debaixo de prisão" ${ }^{51}$.

Avançando ainda mais no tempo, quando as Bolsas de Valores deixaram de ser oficiais e passaram a ser sociedades corretoras, o poder disciplinar foi regulado na Resolução $n^{\mathrm{o}} 39$ de 1966 do $C M N^{52}$.

Neste período, por força da Lei 4.728/65 e da Lei 4.595/64, o BACEN - Banco Central do Brasil detinha a competência para conceder autorizações necessárias ao funcionamento das bolsas de valores no Brasil, e, o CMN - Conselho Monetário Nacional, o poder de regulamentar as bolsas de valores, estabelecendo regras sobre suas condições de constituição, extinção, forma jurídica, organização e funcionamento.

Nos Artigos 104 a 109 do Regulamento Anexo à referida Resolução, foram elencadas diversas penalidades a que se sujeitavam as administrações das Bolsas de Valores, os membros da Bolsa e as administrações das caixas de liquidação, diante da inobservância dos dispositivos legais lá especificados.

Previa-se aplicação de sanções como multa, suspensão, expulsão e inabilitação para exercício de determinados cargos. Quem era competente para determinar tais penas era o conselho de administração das Bolsas.

A partir da edição da Lei 6.385/76, as Bolsas de Valores - até então órgãos auxiliares dos poderes públicos $^{53}$ - foram, de maneira expressa, inseridas na condição de "órgão auxiliar da CVM" sujeita à sua supervisão, no que tange à atuação das Bolsas no exercício dos poderes referidos pelo aludido diploma legal (Artigo 17, § $1^{\mathrm{O}}$ ).

Mantendo a capacidade regulatória do $\mathrm{CMN}$, ficou expresso que a CVM proporia ao CMN normas gerais sobre o "exercício do poder disciplinar pelas bolsas, sobre os seus membros, imposição de penas e casos de exclusão"; (Art. 18, I, d, texto original, Lei 6.385/76) e que as Bolsas de Valores poderiam, em relação aos seus membros e aos valores mobiliários nelas negociados, fiscalizar permanentemente as atividades e os serviços do mercado de valores mobiliários, bem como a veiculação de informações relativas ao mercado, às pessoas que dele participem, e aos valores nele negociados (Artigo 8oㅡ. III, c/c $§ 1^{\circ}$, Lei 6.385/76).

Outras Resoluções do CMN se seguiram: (i) a Resolução no 680 de 1981, (ii) a Resolução de 922 de 1984, (iii) Resolução 1.190 de 1986, (iv) Resolução 1.645 de 1989 (referente ao poder disciplinar das Bolsas de Mercadorias e Futuros), e, (v) Resolução 1.656 de 1989.

$\mathrm{Na}$ Resolução CMN 2.690/00, última das resoluções do CMN sobre a matéria, em seus Artigos 62, 63 e 65, previu-se medidas emergenciais e não emergenciais, conforme fosse a necessidade de instaurar processo administrativo para apurar e julgar as infrações pela Bolsa $^{54}$. Previu-se ainda a possibilidade de que a Bolsa estabelecesse requisitos próprios para a admissão de títulos e valores mobiliários a negociação em seus pregões, bem como as condições de suspensão e cancelamento dessa admissão (artigo 34).

A infração de normas que Bolsa fiscalizava, bem como a utilização de práticas não equitativas, fraude e manipulação, sujeitava os infratores a uma série de sanções: advertência, multa, suspensão, exclusão da sociedade membro, inabilitação para o exercício de cargos de administração de sociedades membros e do sistema de registro ${ }^{55}$.

A Resolução CMN 2690/00 foi revogada com a alteração do Artigo 18 da Lei $6.385 / 76$ pela Lei $10.411 / 02$, tendo sido transferida a competência para 
edição de normas gerais sobre o poder disciplinar das Bolsas para a CVM, ao invés do CMN.

Com a Lei 10.303 de 2001, as Bolsas de Mercadorias e Futuros também foram adicionadas à redação do Artigo 17 , caput e $\S 1^{\circ}$ da Lei $6.385 / 76$ e assumiram a condição de órgão auxiliar da CVM.

Após os processos de integração e desmutualização, um pouco antes que as a operação societária que deu origem à BM\&FBovespa fossem concluída, a CVM editou a Instrução 461 de 2007 (a "ICVM 461/07”), visando reestruturar da organização estrutural e funcional das Bolsas, no que tange ao poder disciplinar destas.

4.6 Essa ICVM 461/07, juntamente com a Lei 6.385/76 e o Regulamento Processual da BM\&FBovespa Supervisão de Mercados - BSM (aprovado por Resolução do antigo Conselho de Administração da BSM em 26/8/2008, com as alterações introduzidas em 16/712010), são os principais instrumentos jurídicos vigentes para entendermos a atual feição do poder disciplinar da Bolsa.

Como comentamos anteriormente, a ICVM 461/07 criou um sistema de autorregulação separado estruturalmente das atividades comerciais da Bolsa, concentrado na BSM - BM\&FBovespa Supervisão de Mercados, associação civil formada pela BM\&FBovespa e o Banco BM\&F de Serviços de Liquidação e Custódia S.A.

Além dessa separação estrutural, há um sistema de separação funcional das atividades relacionadas ao exercício da sua atividade autorregulatória mediante distribuição de poderes entre os órgãos autorreguladores identificados pela Instrução a fim de preservar a independência e redução de conflito de interesses no julgamento dos órgãos autorreguladores ${ }^{56}$.

Nessa esteira, prevê-se a criação do Conselho de Autorregulação, Departamento de Autorregulação e Diretor do Departamento de Autorregulação, órgãos distintos de autorregulação (Artigo 19), dispondo, no Artigo 36, o seguinte:

O Departamento de Auto-Regulação, o Diretor do Departamento de Auto-Regulação e o Conselho de Auto-Regulação são os órgãos da entidade administradora encarregados da fiscalização e supervisão das operações cursadas nos mercados organizados de valores mobiliários que estejam sob sua responsabilidade, das pessoas autorizadas a neles operar, bem como das atividades de organização e acompanhamento de mercado desenvolvidas pela própria entidade administradora.

Seguindo a sistemática da ICVM 461/07, compete ao Departamento de Autorregulação, precipuamente: fiscalizar e supervisionar operações, pessoas, a própria entidade administradora, instruir processos administrativos disciplinares para apurar as infrações das normas legais e regulamentares; propor ao Conselho de Autorregulação a aplicação das penalidades previstas no Artigo 4957, quando cabível; e tomar conhecimento das reclamações efetuadas quanto ao funcionamento dos mercados, acompanhando seu andamento e as medidas decorrentes de seu recebimento ${ }^{58}$.

O Diretor do Departamento de Autorregulação é encarregado da condução dos trabalhos do Departamento de Auto-Regulação ${ }^{59}$, devendo designar comissão de inquérito para instauração de inquérito administrativo, instaurar ou arquivar o inquérito, decidir, por exemplo, sobre produção de provas ou realização de diligências, solicitar parecer jurídico, aplicar as penalidades determinadas pelo Conselho de Autorregulação e julgar processos administrativos de rito sumário ${ }^{60}$. Das decisões do Diretor cabe recurso ao Conselho de Autorregulação (chamado de Conselho de Supervisão, no Regulamento Processual da BSM) ${ }^{61}$.

Por último, cabe ao Conselho de Autorregulação/ Conselho de Supervisão supervisionar as atividades do Departamento de Autorregulação, julgar os processos administrativos de rito ordinário ${ }^{62}$, determinar ao Diretor de Autorregulação a aplicação de penalidades previstas no Artigo 49 da ICVM 461/0763.

Vide esquema abaixo, organizado de maneira sintética a respeito das competências dos órgãos autorreguladores:

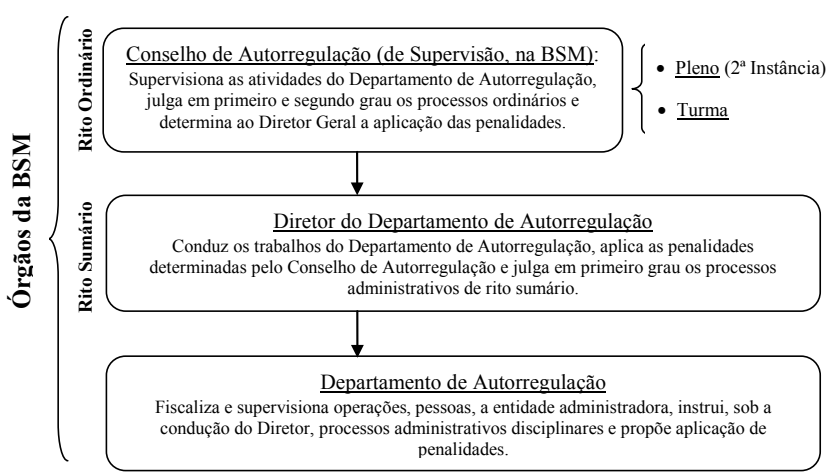

Antes de haver processo administrativo, o Diretor de Autorregulação inicia a apuração da prática de infrações às normas que a BSM deve supervisionar, fiscalizar e auditar, por meio de uma "sindicância". A partir dos indícios verificados, o Diretor decidirá se deverá ser instaurado "inquérito administrativo" (Regulamento BSM, Artigos 5 a 10).

$\mathrm{O}$ inquérito é o meio pelo qual a BSM procede à completa investigação e apuração dos fatos. Novamente, é o Diretor de Autorregulação que decide 
sobre o arquivamento do inquérito ou a instauração do "processo administrativo", se houver elementos de autoria e materialidade da infração (Regulamento BSM, Artigos 11 a 14).

O processo administrativo poderá ser instaurado sobre o rito sumário, se preenchidos os requisitos do Artigo 28 do Regulamento BSM, ou ordinário. Uma vez instaurado, será elaborado "termo de acusação" para a apresentação de defesa, haverá então uma fase de instrução e, por fim, o julgamento (Regulamento BSM, Artigos 15 a 27).

No processo sumário, o julgamento de primeiro grau será feito pelo Diretor de Autorregulação, com recurso para o Pleno do Conselho. No processo ordinário, o julgamento de primeiro grau é realizado por uma Turma de três conselheiros com recurso para o Pleno do Conselho. Via de regra, o recurso possui efeito suspensivo ${ }^{64}$.

O resultado do julgamento dos processos, com as sanções disciplinares aplicadas, deve ser encaminhado à $\mathrm{CVM}$, consoante dispõe o $\S 3^{\mathrm{o}}$ do Artigo 46. No entanto, não cabe recurso à CVM, considerando-se a decisão do Conselho de Autorregulação (Supervisão) final na esfera administrativa ${ }^{65}$.

Cabe notar que os julgamentos dos processos administrativos da BM\&FBovespa estão disponíveis na internet, no site BSM: "http://www.bsm-autorregulacao. com.br/ProcessosAdministrativos.asp".

Ao que nos parece, a maioria dos processos terminam em celebração Termo de Compromisso (Artigos 46 e seguintes do Regulamento BSM), em que os acusados e obrigam a cessar a prática de atividades ou atos considerados infringentes, e, corrigir as irregularidades apontadas, inclusive indenizando prejuízos. Ressalvase que a celebração do termo não representa confissão quanto à matéria de fato ou reconhecimento da ilicitude da conduta. Para uma amostra de processos encerrados com celebração de Termo de Compromisso, vide os Processos Administrativos BSM no $32 / 2012^{66}$ e $n^{\text {o }}$ 05/2010

Sugere-se, ainda, para melhor compreensão do tema, a consulta dos Processos Administrativos Sumários $n^{\circ}$ 62/2012 ${ }^{68}$ e $n^{\circ}$ 53/2012 ${ }^{69}$, para verificar julgamento de processo instaurado em rito sumário, e, a consulta do Processo Administrativo no 11/200970, para análise de julgamento de processo instaurado sob rito ordinário.

Quanto às penalidades a serem aplicadas, há bastante variação.

O Artigo 49 da ICVM 461/07, dispõe que " $a$ violação das normas cuja fiscalização incumba ao Departamento de Auto-Regulação sujeita seus infratores às penalidades previstas em regulamento".
A expressão "regulamento" prevista nesse artigo, na verdade, refere-se, hoje, a diversos regulamentos. Em razão disso, as penalidades variam conforme for o regulamento. Trazemos, abaixo, os principais localizados ${ }^{71}$ :

(i) BSM - Regulamento Processual: um dos mais importantes regulamentos em matéria de poder disciplinar, diversas vezes citado nesse Artigo. Disciplina a instauração, instrução e julgamento de sindicâncias, inquéritos administrativos e processos administrativos. Distribui atribuições entre os seus órgãos, bem como o endereçamento de recursos. Também regula termos de compromissos e multa cominatória por descumprimento de determinações da BSM no curso dos processos ${ }^{72}$.

(ii) BSM - Regulamento de Mecanismo de Ressarcimento de Prejuízos: disciplina o recebimento e julgamento de reclamação dirigida ao Mecanismo de Ressarcimento de Prejuízos - MRP, que tem por finalidade exclusiva assegurar aos investidores, respeitado o limite estabelecido pela CVM, o ressarcimento de prejuízos decorrentes da ação ou omissão de administradores, empregados, operadores e prepostos ${ }^{73}$.

(iii) Regulamento de Operações do Segmento Bovespa (Ações, Futuros e Derivativos de Ações [destinado a Sociedades Corretoras]): disciplina a correção, cancelamento, interrupção e suspensão de negócios, aplicação de multas às Sociedades Corretoras, bem como medidas de emergência - recesso, suspensão atividades, cancelamento de negócios ${ }^{74}$.

(iv) Regulamento de Operações do Mercado de Balcão Organizado (Segmento Bovespa Renda Variável [destinado a Intermediários, Operadores e Formadores de Mercado]): prevê expressamente em seu Capítulo XII o Poder Disciplinar da Bolsa para (a) intermediários: penalidades de advertência, multa, suspensão ou cancelamento do credenciamento para a realização de operações de compra e venda de ativos de Balcão Organizado; (b) para Operadores: advertência ou suspensão da autorização para realizar negócios; e, (c) para Formadores de Mercado: advertência, multa, suspensão do exercício da atividade, cancelamento do credenciamento ${ }^{75}$.

(v) Regulamento de Operações do Mercado de Balcão Organizado (Segmento Bovespa - Renda Fixa Privada [destinado a Participantes]): prevê em seu Capítulo $\mathrm{X}$ o 
Poder Disciplinar da Bolsa, assim como no Regulamento citado no parágrafo anterior, prevendo advertência, multa pecuniária, suspensão e exclusão. Aplicações de medidas emergenciais ${ }^{76}$.

(vi) Regulamento de Operações do Segmento BM\&F (Renda Fixa Pública [Participantes]): prevê, assim como nos dois últimos regulamentos, o Poder Disciplinar da Bolsa no Capítulo V, possibilitando a suspensão das atividades do participante preventivamente; a aplicação de advertência, multa, suspensão, exclusão do participante, ou, inabilitação, temporária ou permanente, para exercício de cargo no Conselho de Administração da BM\&FBovespa e representação perante a mesma $^{77}$.

Por conseguinte, verificamos que, atualmente, há diversos diplomas normativos que informam o poder disciplinar da Bolsa, desde a legislação federal (com a Lei 6.385/76) e instrução normativa da CVM (ICVM 461/07), até regulamentos editados pela própria BM\&FBovespa. Para cada situação, pois, deve-se atentar para os regulamentos próprios da Bolsa, em conjunto com Instruções da CVM e normas gerais constantes da Lei 6.385/76.

\section{CONSIDERAÇÕES FINAIS}

Sem pretensão de esgotar o tema ora objeto de estudo, buscamos analisar o "poder disciplinar" das bolsas de valores, mercadorias e futuros, partindo da verificação de conceitos, características e panorama histórico da "autorregulação" e das "bolsas".

Atualmente concentrado na BM\&FBovespa, o poder disciplinar das bolsas no Brasil decorre da lei $6.385 / 76$, sendo informado pela instrução normativa da CVM 461/2007 e por regulamentos expedidos pela própria BM\&FBovespa. Consiste em fiscalizar e supervisionar sua atividade autorregulatória, coibindo práticas ilegais e não equitativas mediante sanção administrativa, bem como editar normas visando essa finalidade.

Estende-se perante os participantes sujeitos à sua autorregulação e visa manter um sistema adequado à realização de operações realizadas no seu âmbito de atuação, bem como preservar padrões éticos de negociação, outorgando eficácia ao sistema jurídico atinente ao mercado de capitais e às normas editadas pela CVM e BM\&FBovespa.

Dessa feita, ressalta-se a importância da autorregulação - e, consequentemente, do poder disciplinar das bolsas, na medida em que possibilita a fiscaliza- ção e o respeito às normas editadas pela entidade autorreguladora -, seja por alcançar esferas e situações inatingíveis pela mão estatal, seja por complementar a heterorregulação, seja por servir melhor ao mercado de capitais em determinadas situações.

\section{REFERÊNCIAS}

BAPTISTA NETO, José. Bolsas de Valores Mobiliários: estrutura e natureza jurídica. Porto Alegre: Tip. Nacional, 1950.

BARRETO FILHO, Oscar. Natureza Jurídica das Bolsas de Valores no Direito Brasileiro. In: Revista dos Tribunais, n. 283, maio 1959.

COMPARATO, Fábio Konder. Natureza jurídica das bolsas de valores e delimitação do seu objeto. In: Revista de Direito Mercantil: Industrial, Econômico e Financeiro, São Paulo, v. 4, n. 12, p. 243-266, abr.-jun. 2001.

CVM. O mercado de valores mobiliários brasileiro. 2. ed. Rio de Janeiro: Comissão de Valores Mobiliários, 2013.

CALABRÓ, Luiz Felipe Amaral. Teoria Palco-Platéia: a interação entre regulação e autorregulação do mercado de bolsa. Tese (Doutorado) - Faculdade de Direito da Universidade de São Paulo, 2010.

DIAS, Luciana Pires. Regulação e auto-regulação no Mercado de Valores Mobiliários. Dissertação (Mestrado) - Faculdade de Direito da Universidade de São Paulo, 2005.

EIZIRIK, Nelson; GAAL, Ariadna B.; PARENTE, Flávia; HENRIQUES, Marcus de Freitas. Mercado de capitais - regime jurídico. 3. ed. Rio de Janeiro: Renovar, 2011. p. 179-207.

FRANCO, Vera Helena de Mello; SZTAJN, Rachel. Manual de direito comercial. São Paulo: Revista dos Tribunais, 2005. v. 2.

GUERREIRO, José Alexandre Tavares. Sobre o poder disciplinar da CVM, In: Revista de Direito Mercantil (nova série), ano XX, n. 43, 1981.

MATTOS FILHO, Ary Osvaldo. Natureza jurídica das atividades das Bolsas de Valores. In: Revista dos Tribunais, ano 75, jan. 1986.

MEIRELLES, Helly Lopes, Direito Administrativo Brasileiro. 25. ed. São Paulo: Malheiros Editores, 2000. p. 122.

MOREIRA, Vital. Auto-regulação profissional e administração pública. Coimbra: Almedina, 1997.

MURRAY, James M. Bruges, cradle of capitalism, 1280-1390. Cambridge: Cambridge University Press, 2005.

SALLES, Marcos Paulo de A. Os valores mobiliários na Lei das S/A. In: Revista de Direito Mercantil (nova série), ano XXXVI, n. 107, 1997.

SZTAJN, Rachel. Regulação e Mercado de Valores Mobiliários. In: Revista de Direito Mercantil, n. 135, 2004.

TRINDADE, Marcelo; SANTOS, Aline de Menezes. Regulação e auto-regulação no Brasil e a crise internacional, 2009 (artigo).

YAZBEK, Otávio. Regulação no Mercado Financeiro de Capitais. 2. ed. Rio de Janeiro: Elsevier, 2009.

YAZBEK, Otávio. A regulamentação das bolsas de valores e das bolsas de mercadorias e futuros e as novas atribuições da comissão de valores mobiliários. In: Revista de Direito Bencário e do Mercado de Capitais, ano 9, n. 34, out.-dez. 2008.

WALD, Arnoldo. EIZIRIK, Nelson. O regime jurídico das bolsas de valores e sua autonomia frente ao Estado. In: Revista de Direito Mercantil, ano XXV, n. 61, p. 6, jan.-mar. 1986.

WARDE JÚNIOR, Walfrido Jorge. A desmutualização das bolsas de valores e os novos desafios da regulação dos mercados de capitais. In: Revista de Direito Mercantil: Industrial, Econômico e Financeiro, São Paulo, v. 45, p. 128-137, out. 2006. 


\section{NOTAS}

${ }^{1}$ Conforme nos ensina WALD, Arnoldo. EIZIRIK, Nelson. O regime jurídico das Bolsas de Valores e sua autonomia frente ao Estado. In: Revista de Direito Mercantil, ano XXV, n. 61, p. 6, jan.-mar. 1986,

2 RACHEL, Sztajn. Regulação e o Mercado de Valores Mobiliários. In: RDM - Revista de Direito Mercantil, n, 135, 2004, p. 137.

3 Para não escapar dos lindes deste artigo, analisaremos aprofundadamente apenas o conceito de autorregulação.

${ }^{4}$ DIAS, Luciana Pires. Regulação e Auto-regulação no Mercado de Valores Mobiliários. Faculdade de Direito da Universidade de São Paulo (Dissertação), 2005, p. 118-120.

${ }^{5}$ MOREIRA, Vital. Auto-Regulação Profissional e Administração Pública. Almedina, Coimbra, 1997, p. 52 e ss.

${ }^{6}$ TRINDADE, Marcelo. SANTOS, Aline de Menezes. Regulação e Autoregulação no Brasil e a Crise Internacional, 2009 (artigo). p. 13

7 DIAS. Regulação e Auto-regulação..., p. 118-120.

${ }^{8}$ Quando se faz referência nesse estudo ao termo "Bolsas" quer dizer de maneira ampla as Bolsas de Valores, de Mercadorias e de Futuros.

9 YAZBEK, Otávio. Regulação no Mercado Financeiro de Capitais. 3. ed., Rio de Janeiro, Elsevier, 2009. p. 212.

${ }^{10}$ DIAS. Regulação e auto-regulação..., p. 131.

11 YAZBEK, Otávio. A regulamentação das bolsas de valores e das bolsas de mercadorias e futuros e as novas atribuições da comissão de valores mobiliários. In: Revista de Direito Bencário e do Mercado de Capitais, ano 9, n. 34, out.-dez. 2008, Editora Revista dos Tribunais, p. 206.

12 YAZBEK. Regulação..., p. 212.

13 YAZBEK. Regulação..., p. 212.

14 MURRAY, James M. Bruges, cradle of capitalism, 1280-1390. Cambridge University Press, 2005, p. 179-180.

${ }^{15}$ BARRETO FILHO, Oscar. Natureza jurídica das Bolsas de Valores no Direito Brasileiro. In: Revista dos Tribunais, n. 283, p. 07-10, maio 1959.

${ }^{16}$ WALD. EIZIRIK. O Regime..., p. 12.

${ }_{17}$ Disponível em: <http://www2.camara.leg.br/legin/fed/decret/1824-1899/ decreto-417-14-junho-1845-560499-publicacaooriginal-83429-pe.html> (acesso em: set. 2014).

18 Disponível em: <http://www2.camara.leg.br/legin/fed/decret/1824-1899/ decreto-648-10-novembro-1849-559883-publicacaooriginal-82317-pe. html $>$ (acesso em: set. 2014).

19 Disponível em: <http://www2.camara.leg.br/legin/fed/decret/1824-1899/ decreto-806-26-julho-1851-559495-publicacaooriginal-81755-pe.html> (acesso em: set. 2014).

${ }^{20}$ Disponível em: <http://www.planalto.gov.br/CCIVIL_03/decreto/ Historicos/DIM/DIM6132.htm> (acesso em: set. 2014).

${ }^{21}$ Disponível em: <http://www2.camara.leg.br/legin/fed/decret/1824-1899/ decreto-1359-20-abril-1893-523045-publicacaooriginal-1-pe.html> (acesso em: set. 2014).

22 A primeira referência expressa às Bolsas Estaduais foi realizada no Decreto 24.275/1934.

${ }^{23}$ Para mais informações a respeito dessa discussão ver: BARRETO FILHO. Natureza Jurídica..., p. 07/31 (ressalvando que não se tratava de autarquia, mas sim pessoas jurídicas de direito privado) e BAPTISTA NETO, José. Bolsas de Valores Mobiliários: estrutura e natureza jurídica. Porto Alegre: Tip. Nacional, 1950, p. 16 (no sentido de que as Bolsas seriam entidades autárquicas na subespécie corporações de disciplina mercantil).

${ }^{24}$ Muito embora assegurou-se que aqueles que já tivessem tal prerrogativa permanecessem a exercê-la.

${ }^{25}$ MATTOS FILHO, Ary Osvaldo. Natureza Jurídica das atividades das Bolsas de Valores. In: Revista dos Tribunais, ano 75, v. 3, p. 34, jan. 1986.

${ }^{26}$ Para ter uma visão mais detalhada sobre o processo de desmutualização das Bolsas verificar EIZIRIK, Nelson. GAAL, Ariádna. PARENTE, Flávia. HENRIQUES, Marcus de Freitas. Mercado de Capitais: regime jurídico. 3. ed. Rio de Janeiro: Renovar, 2011, p. 216-225.

27 Posteriormente, passou a se chamar BM\&F Bovespa Supervisão de Mercados, entidade responsável pela autorregulação dos mercados da BM\&FBovespa. Atualmente, os associados da BSM são a BM\&FBovespa e o Banco BM\&F de Serviços de Liquidação e Custódia.

${ }^{28}$ EIZIRIK et. al., Mercado de Capitais... p. 223-224. O autor também chama atenção para a separação funcional, que consiste na criação de órgãos específicos, dentro da própria estrutura administrativa da bolsa, com a função de administrar, de maneira exclusiva, todas as questões referentes à atividade autorregulatória das Bolsas. Isso também é observado pela BSM, conforme se verá adiante.
${ }^{29}$ MATTOS FILHO, Natureza Jurídica..., p.34

${ }^{30}$ Conforme se verifica no Acervo Histórico do site da BM\&FBovespa, disponível em: < http://www.acervobmfbovespa.com.br/History> (acesso em: set. 2014): "As bolsas de valores, embora ainda não tivessem esse nome, foram instituidas oficialmente no país por meio de vários decretos imperiais em 1851".

${ }^{31}$ EIZIRIK, et al. Mercado de Capitais..., p. 211.

32 YAZBEK. Regulação..., p. 216.

33 YAZBEK. Regulação..., p. 212

${ }^{34}$ DIAS. Regulação..., p. 121.

${ }^{35}$ EIZIRIK. et al. Mercado de Capitais..., p. 210

${ }^{36}$ YAZBEK. Regulação..., p. 214.

37 No entanto, indaga-se se, em razão do interesse público da função prestada pela Bolsa, a atuação desta não ocasionaria em, ao invés de uma faculdade, um dever de punir o infrator? Por exemplo, não seria dever da BM\&FBovespa exercer seu poder disciplinar no caso de pessoa autorizada a operar em seu mercado ter criado condições artificiais ou fraudulentas de oferta e demanda?

${ }^{38}$ GUERREIRO, José A. Tavares. Sobre o Poder Disciplinar da CVM, Conferência pronunciada na Comissão de Valores Mobiliários em 8.5.1981. In: RDM - Revista de Direito Mercantil, Industrial, Econômico e Financeiro (nova série), ano XX, n. 43, p. 64, jul.-set. 1981.

${ }^{39}$ Conforme Lei 6385/76, Artigo 17, caput e $\S 1$ o. Ressalva-se que, para WALD e EIZIRIK, O regime jurídico..., p. 18, "as Bolsas são consideradas 'órgãos auxiliares da CVM', apenas no que se refere ao exercício do seu poder de polícia frente aos seus associados".

${ }^{40}$ Lei 6385/76, Artigo 17, caput.

${ }^{41}$ ICVM 461/07, Art. 49, § $3^{\circ}$.

${ }^{42}$ ICVM 461/07, Art. 82, § único. Cumpre destacar, consoante informações do site www.bomfbovespa.com.br ,que o Mecanismo de Ressarcimento de Prejuízos (MRP) tem a finalidade exclusiva de assegurar aos investidores o ressarcimento de prejuízos decorrentes da ação ou omissão de participante e agente de compensação ou de custódia, ou de seus administradores, empregados ou prepostos, em relação à intermediação de negociações realizadas na Bolsa. O MRP é administrado pela BSM.

${ }^{43}$ Regulamento BSM, Artigos $3^{\circ}, 4^{\circ}, 10, \S 2^{\circ}$ e 12, e, ICVM 461/07, Arts. 28, X e XI, 37, III, § 4⿳⺈,40, 44, 45, I, 46, § $3^{\circ}$, $49, \S 1^{\circ}$.

${ }^{44}$ Lei 6385/76, Arts. 11, $\S 10^{\circ}, 18$; e, ICVM 461/07, Art. 46, § 1으, I e Art. $7^{\mathrm{o}}, \S 2^{\mathrm{o}}$

${ }_{45}$ ICVM 461/07, Art. 49, $\S \S 5$ e $6^{\circ}$.

${ }^{46}$ Regulamento BSM, Artigos 29 e 30.

47 GUERREIRO, Sobre o poder..., p. 73.

${ }^{48}$ MEIRELLES, Helly Lopes, Direito Administrativo Brasileiro. 25. ed. São Paulo: Malheiros Editores, 2000, p. 122.

${ }^{49}$ Ressalva-se que os modernos conceitos de poder disciplinar e de poder de polícia são conceitos emprestados do direito público, geralmente associados a instituições pertencentes à administração pública direta ou indireta, mas que vem sendo utilizados pela doutrina a respeito das instituições autorregulatórias privadas lidam com assuntos de interesse público.

${ }^{50}$ CALABRÓ, Luiz Felipe Amaral. Teoria Palco-Platéia: a interação entre regulação e autorregulação do Mercado de Bolsa. Tese (Doutorado) Faculdade de Direito da Universidade de São Paulo, 2010, p. 95-96.

${ }^{51}$ Artigo 61 e 62 c/c Artigo 20 do Código Comercial.

52 GUERREIRO, Sobre o poder..., p. 72.

53 Conforme Lei 2.146 de 1953, anteriormente à existência da CVM, as Bolsas de Valores eram "órgãos auxiliares dos poderes públicos, na fiscalização dos lançamentos de emissões de títulos, por subscrição pública".

54 Atualmente, o Artigo 64 da ICVM 461/07 prevê, similarmente, a possibilidade de aplicação de medidas cautelares pela Bolsa, com "o objetivo de assegurar o funcionamento eficiente e regular do mercado ou preservar elevados padrões éticos de negociação". Assim, segundo a Instrução, a Bolsa pode decretar o próprio recesso, em caso de grave emergência, comunicando o fato imediatamente à CVM (Inciso I); suspender, provisoriamente, pessoa autorizada a operar, quando a proteção dos investidores assim o exigir, comunicando, de imediato, a ocorrência à CVM, ao Banco Central do Brasil e ao Diretor do Departamento de Auto-Regulação (Inciso III); impedir a realização de certas operações em seus ambientes de negociação, quando existirem indícios de que possam configurar infrações a normas legais e regulamentares (Inciso IV); e cancelar negócios realizados, desde que ainda não liquidados, ou suspender a sua liquidação, ou solicitar à entidade de compensação e liquidação a suspensão, caso haja indícios de que possam configurar infrações a normas legais e regulamentares (Inciso V). 
55 Artigo 65, incisos I a V.

56 Conforme possibilita a ICVM 461/07, Artigos 36, §3o e 37, I.

57 Trata-se de penalidades previstas em regulamentos a serem elaborados pela própria Bolsa, conforme veremos em seguida.

58 ICVM 461/07, Artigo 43.

59 ICVM 461/07, Artigo 38.

${ }^{60}$ BSM, Regulamento Processual, Artigo 11, § 1ํㅡ, 13, I e II, 20, 24, 28 e ICVM 461/07, Artigo 46, $\S 1^{\circ}$.

${ }^{61}$ BSM, Regulamento Processual, Artigos 13, § único, 20, 27, II, 'a' e III, $28, \S 3^{\circ}$.

62 ICVM 461/07, Artigo 46 e Artigo 25 do Regulamento Processual da BSM.

${ }^{63}$ Importa salientar que mesmo dentro do Conselho de Supervisão, os julgamentos de $1^{\text {a }}$ Instância serão julgados por uma Turma composta por 3 membros do Conselho de Supervisão (Art. 26, Reg. Proc. BSM), os julgamentos de $2^{\mathrm{a}}$ instância serão julgados pelo pleno do Conselho de Supervisão (Arts. 27, § 1ํㅡㄴ 38 e 39).

${ }_{64}$ Regulamento BSM, Artigo 27.

65 ICVM 461/07, 49, § 3ำ e Regulamento Processual da BSM, Artigo 45. Ressalvada a exceção prevista no Artigo 82, § único da ICVM 461/07.

${ }^{66}$ Ementa: "Envolvidos: Corretora, Diretor para o mercado de ações, Sociedade de agente autônomo de investimento e Agente autônomo de investimento. Descrição. Indícios de atuação irregular de agente autônomo, aconselhando clientes a realizar negócios, com finalidade de obter, para si ou para outrem, vantagem indevida. indicios de adoção de práticas capazes de ferir a relação fiduciária entre cliente e corretora. indícios de execução de ordens emitidas por terceiro que não constava da ficha cadastral como procurador devidamente constituido. Celebração de termo de compromisso. Cumprimento integral das obrigações assumidas. Encerramento do processo."

67 Ementa: "Não conformidade dos controles e dos procedimentos operacionais da Corretora apurados em relatório de auditoria. Celebração de termo de compromisso. Comprovação de adoção de aperfeiçoamento dos controles internos. Cumprimento integral das obrigações assumidas. Encerramento do processo."
68 Ementa: "Envolvidos: Corretora e Operador. Day-trade em negócios diretos. Mercado de opções. Favorecimento de cliente na realização de negócios. Indícios de uso de práticas não equitativas. Celebração de termo de compromisso. Cumprimento integral das obrigações assumidas. Encerramento do processo."

69 Ementa: "Envolvidos: Corretora XP Investimentos CCTVM S.A. e Décio Lazzarato, agente autônomo de investimentos. Atuação irregular de agente autônomo. Recebimento de numerário diretamente do investidor e consequente quebra do dever fiduciário. Decisão DAR. Condenação. Trânsito em julgado. Encerramento do processo no âmbito da BSM."

70 Ementa: Falhas nos controles internos da corretora relacionados à prevenção e ao combate à lavagem de dinheiro. Operações atípicas de alto volume e risco, incompativeis com o conhecimento e a movimentação de recursos, a atividade econômica e a capacidade financeira da investidora. Julgamento pela turma do conselho de supervisão. Absolvição da corretora. Arquivamento do processo, em razão da efetiva atuação da área de compliance da corretora. Encerramento do processo.

71 Por escapar os limites do presente Artigo, não analisaremos detalhadamente cada regulamento indicado, destacando, apenas, de forma genérica, a sua função.

72 Disponível em: <http://www.bsm-autorregulacao.com.br/InstDownload/ BSM-Regulamento-Processual.pdf $>$ (acesso em: set. 2014).

73 Disponível em: <http://www.bsm-autorregulacao.com.br/InstDownload/ BSMRegulamentoMRP.pdf $>$ (acesso em: set. 2014).

74 Disponível em: <http:/www.bmfbovespa.com.br/pt-br/regulacao/ download/0_manual_regula_completo.pdf> (acesso em: set. 2014).

75 Disponível em: <http://www.bmfbovespa.com.br/pt-br/regulacao/ download/Regulamento-de-operacoes-do-mercado-de-balcao-Completo. pdf> (acesso em: set. 2014).

76 Disponível em: <http://www.bmfbovespa.com.br/pt-br/regulacao/ download/Regulamento-de-Operacoes-SOMA-FIX.pdf $>$ (acesso em: set. 2014).

77 Disponível em: <http://www.bmfbovespa.com.br/pt-br/regulacao/ download/Regulamento-de-Operacoes-do-Segmento-BMF-Renda-FixaPublica-Titulos-Publicos-Federais-Sisbex.pdf $>$ (acesso em: set. 2014).

Recebido em: 30/10/2014; aceito em: 04/11/2014 